\title{
Science and Education: A Perspective of Didactic Transposition with Bioinformatics Concepts
}

\author{
Gabriel Dall'Alba, Guilherme Brambatti Guzzo, Scheila de Avila e Silva \\ University of Caxias do Sul
}

\begin{abstract}
The large amount of scientific information available nowadays challenges the capacity of students to deal appropriately with it. This may result in a loss of interest on the subject and, thus, create a gap between scientific ideas and the students. In order to avoid this, didactic transposition and interdisciplinary methods might bring in new thoughts on how science education can be improved. In this paper, we discuss the application of those ideas by using Bioinformatics as an example, as it has been an emerging field that is based on interdisciplinary approaches. By improving the teaching of complex ideas and theories, it is possible that the student's relationship with science, as well as with the educators, may be improved.
\end{abstract}

\section{Introduction}

In 1988 , an international organization called Human Genome Organization (HUGO) was founded in order to carry out the Human Genome Project. By the year of 2001, the release of the draft version of the Human Genome concluded the first phase of the project [1]. At this moment, bioinformatics began to play an important role in life sciences.

The amount of data released with the results of the project was big enough to create a new challenge: how to manage all the data. From this question emerged the requirement of developing of databases, such as GenBank [2] and EMBL [3], in order to store and manipulate the DNA sequences coming from the Human Genome Project and other genome sequencing projects.

The amount of research projects after the Human Genome Project shows the application of technology in Biology. This scenario is moving biology to a new perspective, setting it as an informational science [4]. As a result, technologies from other fields are being used to analyze biological data.

Nowadays, bioinformatics broadens the sequencing projects. This field embraces sequences analysis, structural analysis, genome annotation, computational and evolutionary biology, gene and protein expression and regulation, among others. It is a well-established science, contributing to a wide variety of disciplines in the life sciences [5].
Interdisciplinary approaches facilitate the understanding of complex issues. For this reason, education's interest on interdisciplinary methods increased over the past years [6], [7]. The focus on domain-specified knowledge is being surpassed by the development of cross-boundary skills.

Interdisciplinary research is defined as the integration of two or more scientific disciplines to solve a specific problem [8]. Life sciences are no longer defined exclusively by biology. They are composed by an integrated study of biology, chemistry, physics, mathematics, statistics and informatics [4]. Researches involving biological data are not constrained to a few types of information. Instead, there is a wide range of data (see Table 1), from genetic sequences, protein function, medical findings, ecological questions and so on [4].

Table 1. Some of the types of biological data throughout researches

\begin{tabular}{|l|}
\hline \multicolumn{1}{|c|}{ Types of biological data } \\
\hline Sequences (DNA, RNA, Protein) \\
\hline Structures of biological molecules \\
\hline Gene expression profiles \\
\hline Biochemical pathways \\
\hline Chromosomal mapping \\
\hline Phylogenetic data \\
\hline Single Nucleotide Polymorphisms \\
\hline
\end{tabular}

(Source: www.kirkwood.edu/pdf/.../lecture1-intro\&online_sources.pdf, accessed 09/28/16)

The growth of data in biology, chemistry, physics (also known as "big sciences") has led Bioinformatics to raise new perspectives in: new drugs discovery, information on Earth's climate, better ways to analyze history and culture, and to investigate topics related to biology (genomics, proteomics, metabolomics, among others), physics and, most recently, advances in medicine (better pre-clinical and clinical trials, application of sequencing on a patient's genome, and preventive medicine) [4], [8].

The constant advances in science amplify the amount of information available. One of the goals of educators is to ensure that the student acquire interest in the scientific matters. However, the vast number of information challenges the student capacity to deal 
with the complexity of scientific data. There is a need of building a connection between the scientific information and the student.

Didactic transposition, as proposed by Michel Verret [9] and revisited by Yves Chevallard [10], involves the pathway that the knowledge takes from scientific researches to the school. Being adapted and shaped in a way that eliminates or simplify more difficult features of a specific topic. In this context, science educators are the ones responsible for aiding in this transition.

Chevallard conceptualizes didactic transposition as the construction of a learning tool, which means, turning a scientific product into school knowledge. The relationship Science-Education is set when educators encouraged students to critically discuss it. [11].

From this perspective, the present paper aims to discuss the role of the scientific discoveries in the basic education considering the concepts of didactic transposition. Besides, interdisciplinary concepts are contextualized by using bioinformatics as example that can provide new thoughts on how to improve science education.

Aiming at achieving this goal, the present study is organized in two main sections. Section 2 describes the application of didactic transposition in school. The Section 3 details the link between bioinformatics and the didactic transposition. This is an important topic for understanding how the addressed concepts can be applied together. Finally, the section 4 presents the conclusions of this paper.

\section{Didactic Transposition in life sciences education}

Scientific information is widely available to public access. However, technical concepts and theories are not easily understood by lay people. A student may find difficulties in comprehending certain ideas and, therefore, not being able to interpret a paper's content [12]. In this context, a gap between the student and science is created. This can turn into a loss of interest in scientific topics and disciplines, diminishing interactions between the student and the educator [13] and less interest in comprehension of daily events.

In order to avoid this loss of enthusiasm in students, science teaching must be strengthened. An educator can aid in building the bridge connecting science and students proposed by the didactic transposition. The required effort from a teacher in order to refine scientific information is big, however, rewarding [12]. In Table 2, some guidelines are presented in order to better prepare the educators when presenting a scientific idea to a classroom through didactic transposition concepts (see Table 2).

The process of rewording scientific information need to be carefully carried out by the educator in order to reduce the gap between the students and the science. This topic is highlighted by Franzolin [14], who discusses two types of distances resulting by didactic transposition, the horizontal and the vertical distancing from a scientific topic and its contextualization in the school.

Table 2. Guideline for educators when presenting a scientific idea to a classroom through didactic transposition concepts

\begin{tabular}{|c|c|}
\hline $\begin{array}{l}\text { When presenting a scientific idea to a classroom, } \\
\text { the educator must be prepared to }\end{array}$ \\
\hline (i) & $\begin{array}{l}\text { Properly understand the } \\
\text { subject }\end{array}$ \\
\hline$($ ii) & $\begin{array}{l}\text { Swap scientific terms } \\
\text { into more accessible for } \\
\text { the students }\end{array}$ \\
\hline (iii) & Organize, sustain and \\
& explain the main \\
concepts approached \\
through a more \\
simplified and \\
enlightening text, \\
presentation or practical \\
activity \\
\hline
\end{tabular}

The vertical distancing is originated from the transposition of scientific concepts for different levels of education, in order to facilitate its comprehension. This distancing does not present itself as a problem, as it does not result in loss of meaning of the concept presented. In a certain way, topics with greater rigidity in their concepts often are found within this distancing. For instance, Franzolin affirms that the content found on didactic books about genetics for high school presents itself as a vertical distancing. So the content from these books are in accordance to the bibliographic references [15].

According to Griffiths [15], the gene concept is “... The physical and fundamental unity of heredity, which takes information from one generation to the next". The same concept is found on a didactic book for seventh grade: "What is the gene? The unity of hereditary transmission, formed by a chemical substance, the DNA." (Book D-EF, Seventh Grade, p. 189). In this case, the distancing is classified as vertical [14].

The main problem from the distancing is when the original concept is replaced mainly by conceptual errors or by common sense information, sometimes, even pseudoscience [16]. For instance, the exoskeleton in arthropods, instead of being addressed as "external skeleton", it is addressed as a "shell, carapace or armor" [14]. In this case, the distancing is classified as horizontal [14], as it is different from the references and does not represent the original concept correctly. In Figure 1 both distancing are represented. The circle A represents the vertical distancing from the genetics example and the circle $\mathrm{B}$ represents the horizontal distancing from the 
exoskeleton example (Figure is based on Franzolin [14] idea).

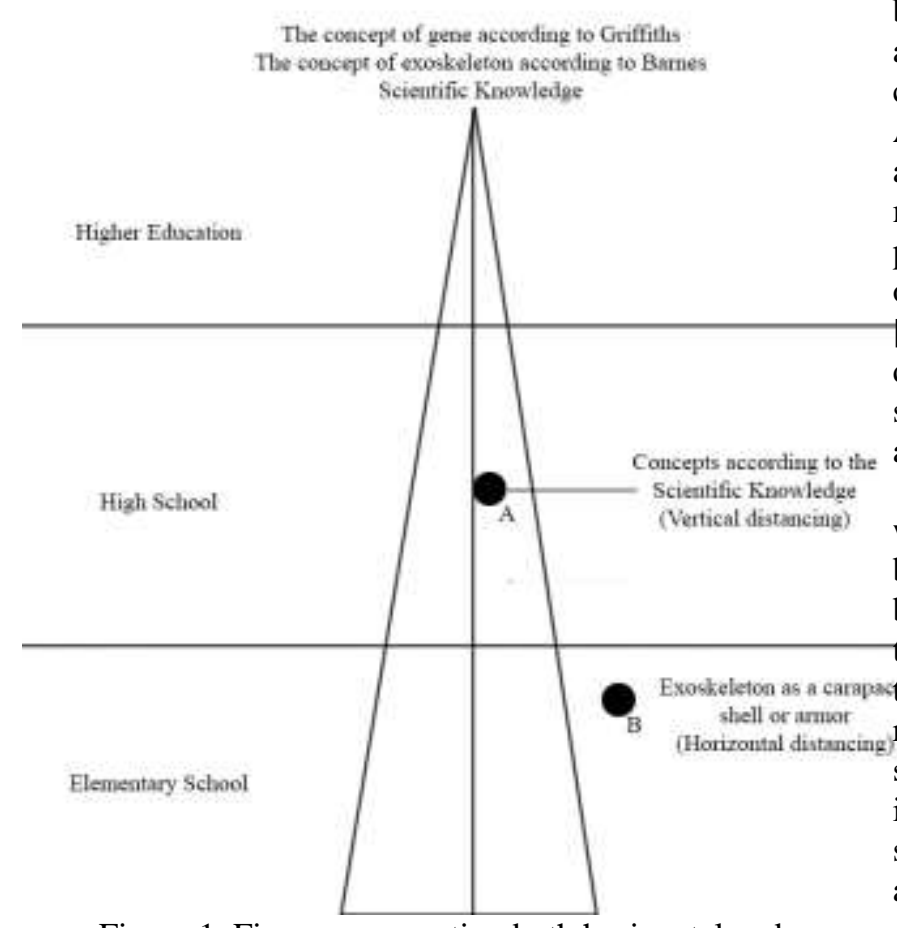

Figure 1. Figure representing both horizontal and vertical distancing inside the different levels of education.

It is essential for educators to be aware of the horizontal distancing, in order to avoid the misunderstanding of scientific ideas or of the process of scientific inquiry among the students. Topics that present this kind of misconceptions make it difficult for the students to understand them, and also might hamper a better understanding of the mechanisms of science. The results of this may appear over time, when students face difficulties to utilize appropriately the scientific knowledge, or to think critically on subjects related to science, on every day and school matters.

Bioinformatics inside the classroom has already been addressed in multiple papers over the past years. Kovarik et al. address the teaching of bioinformatics in High School. The main goal was to apply the Bio-ITEST: New Frontiers in Bioinformatics and Computational Biology program and curricula in order to prepare secondary science teachers with the appropriate tools (i.e. skills, resource materials and didactic) to encourage students to understand and participate at the bioinformatics and related fields in biology [17].

Two distinct curriculums were used: (i) Introductory Curriculum: Using Bioinformatics: Genetic Testing and (ii) Advanced Curriculum: Using Bioinformatics: Genetic Research. On the first curriculum, students were introduced - throughout 7 lessons - to bioinformatics tools and concepts and the ethical issues surrounding genetic testing. After this, they investigated the genetic and molecular consequences of a mutation on a specific gene connected to Breast Cancer susceptibility.
On the second curriculum, the emphasis is on specific research. By using the DNA barcoding method (a taxonomic method that identify if a DNA belongs to a specific species [18] [19]), the students apply this technique on the mitochondrial-encoded cytochrome $c$ oxidase subunit 1 (COI) gene. According to the authors, there are multiple advantages by using this gene: the gene is mitochondrial, which means it is more abundant, less prone to degradation and lacks introns in many organisms, simplifying the analysis that can be made [17]. Throughout 9 lessons the students analyze the data and make researches on databases. Also, the students update their résumés, write a cover letter and simulates a job interview.

Both curriculum are performed with professionals who uses or work is made possible by bioinformatics. Also, the teachers learn about bioinformatics and the Bio-ITEST program through two workshops. The key element of this approach is the incorporation of authentic bioinformatics research projects as a method to increase the student's interest on the matter. Furthermore, it increases the interdisciplinary understanding of the scientific process and correlates it with possible daily activities of students.

Statistical results evidence that both teachers and students had increased their interest on bioinformatics and related biology fields after the workshops / curriculum. Not only students and teachers felt more comfortable when dealing with bioinformatics concepts and software, but also when dealing with scientific information.

Wefer and Sheppard evidence that bioinformatics is not included in any of the 49 U.S. states that were analyzed. However, terms that can be associated with bioinformatics to a certain degree (i.e. Human Genome Project, genomics, forensics, medicine and evolution) can be found within the High School Biology Curricula [20]. Due to this, bringing bioinformatics and related areas into the school environment (via workshops, courses and other activities) can be a step towards eliminating the gap that exists between scientific knowledge from these areas and the classroom.

Brazas et al. bring new insights on how bioinformatics can aid both clinical and public audiences through training on bioinformatics. The authors identifies both the needs from the clinical audience (i.e. how to manage data and understanding of output from bioinformatics analysis of genomic data) and from the public audience (i.e. understanding the implications of genomics and bioinformatics) [21].

While the clinical audience is better acquainted on scientific terms, addressing the public audience poses some challenges, such as being affected by misinformation from the media and lacking the basics of genetics and related trends. [21]. In order to address this public, a viable way is through: $(i)$ open access material; (ii) multiple social media resources; (iii) engaging and informative content (i.e. eye-catching displays); (iv) trusted information 
sources; $(v)$ simplified concepts and (vi) presentation of concepts in a clear and concise manner [21].

It is important to highlight that simplifying concepts and presenting them in a clear and concise manner can be achieved through didactic transposition, provided that the knowledge don't diverge from its main concepts [14]. In addition, the use of bioinformatics as a tool for teaching biology and the teaching of bioinformatics itself present opportunities to address some of the challenges mentioned by Brazas et al. As the authors comment: "One long-term solution to improving public literacy is to bring genomics and bioinformatics into the formal high school classroom".

Didactic transposition offers a different perspective when aiming at approximating the student to the scientific fields. This approach aims to organize the scientific content, allowing the student to deal with scientific information on a more accessible language. In addition to that, the student is encouraged to investigate and comprehend more challenging issues, a process that facilitates the development of critical thinking [12].

\section{Bioinformatics in Education}

Bioinformatics comprises a variety of interdisciplinary methods that are related to life sciences. Due to this, Bioinformatics can be introduced as a tool to assist the teaching of certain areas of biology. An interdisciplinary approach, via Bioinformatics, can improve the organization of complex ideas. Furthermore, alternative teaching methods can motivate the student to investigate and comprehend the topics being presented [13].

The complexity of certain scientific concepts may pose some difficulties for the students to learn them. For example, in genetics, there are misconceptions of what a gene and DNA mean [22]. In this way, the students can easily compound the gene concept merging it with metaphorical models.

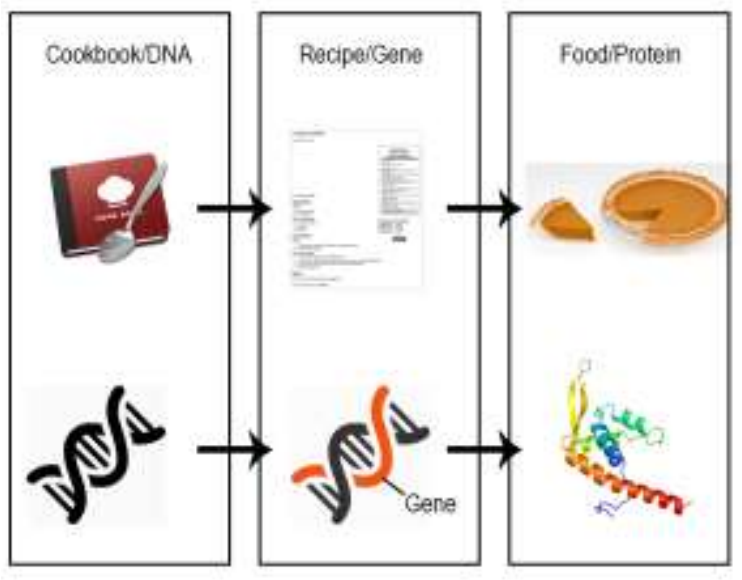

Figure 2. The "gene as a recipe" metaphor

The analogies are: (i) DNA as a cookbook, (ii) the gene as a recipe and (iii) the protein as the food
These models often portray the gene as a particle with certain effects related to it and as a sequence of instructions [22]. One metaphorical model is the gene as a recipe (see Figure 2).

Based on the analysis made by Franzolin [14], this model can be classified as a horizontal distancing. Mainly because the "one gene-one protein" idea, idealized in 1941, is not the most up-to-date information available. Emerging evidences after the HGP indicates that one single gene can result in multiple products [23] (see Figure $3)$.

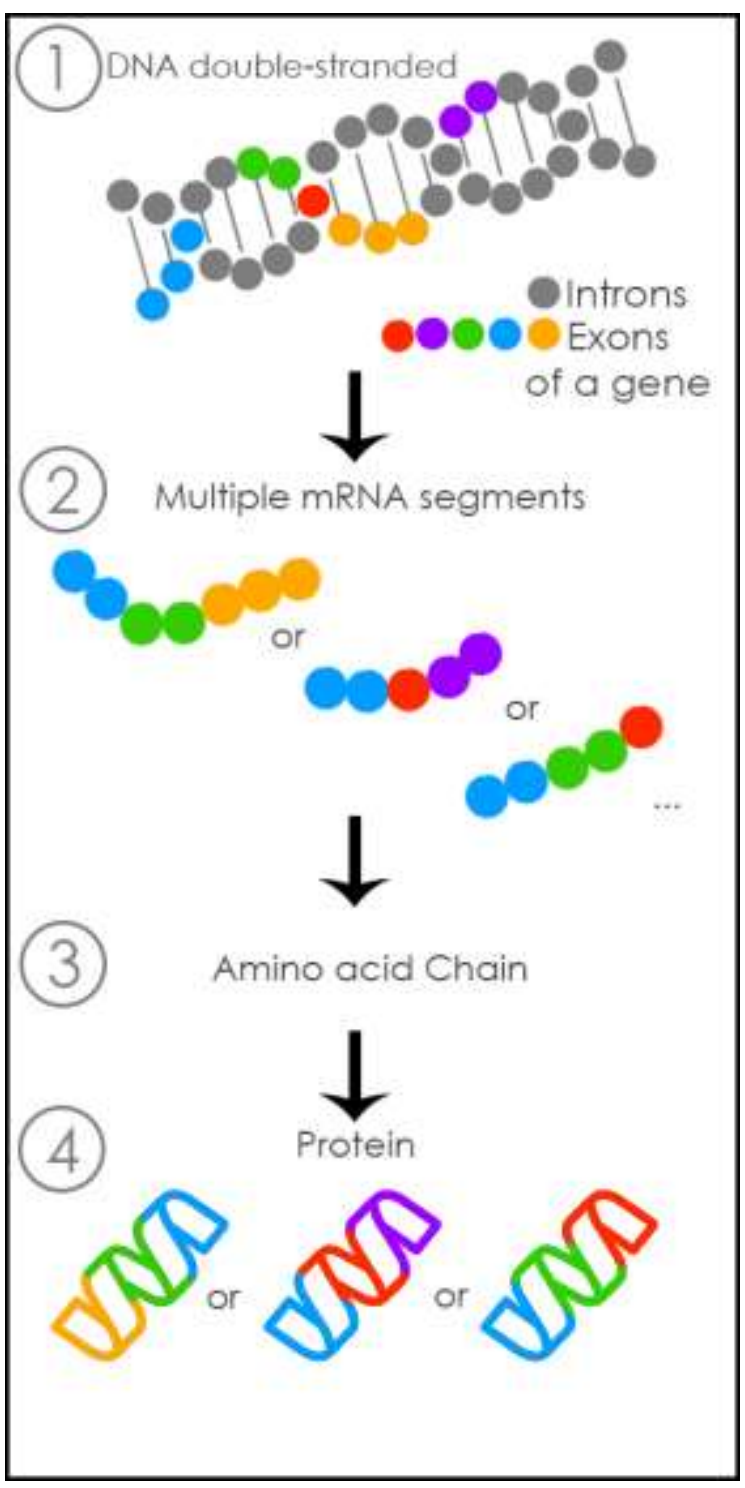

Figure 3. Illustration representing how one gene can result in multiple proteins:

(i) Item 1 shows a representation of a gene and its exons (multiple parts of a gene that are used for transcription) present in different regions of the DNA;

(ii) Item 2 illustrates messenger RNA segments with different combinations of exons;

(iii) Item 3 represents the amino acid chain built from the mRNA sequence and

(iv) item 4 represents the different protein structures that may emerge from distinct combinations of 
exons. Based on Lucy Reading-Ikkanda's illustration [23].

From the standpoint of didactic transposition, Bioinformatics researches can be applied in order to improve the student's comprehension about genetics. Since these projects are related to proteins, DNA and RNA issues [5]. This can be achieved by videos, softwares and associated tools [21]. Some examples are available in "John Kyrk Cell Biology Animations" [24] and "DNA from the Beginning" [25] websites (figure 3).

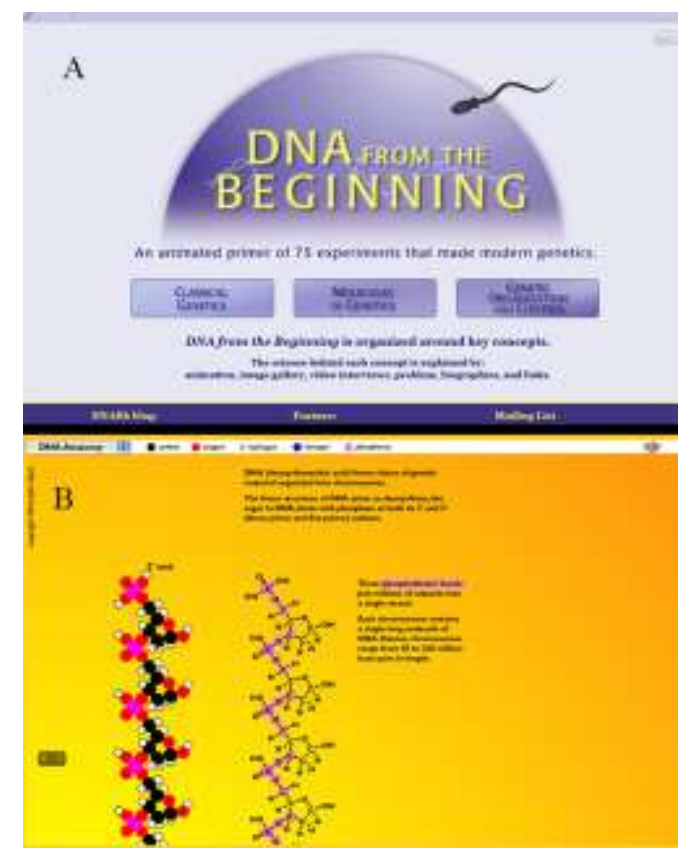

Figure 4. User interface from: (A) DNA from the Beginning [24] and (B) John Kyrk Cell Biology

Animations [25]. Both tools offer a clear visualization on different topics of biology, including interdisciplinary approaches

A visualization on topics that are harder to conceive allows a better comprehension of them [6]. In those moments, the informatics tools assist in making abstract concepts real. Which, in turn, provides the key elements to link those concepts with other important topics (i.e., the link between genetic material and cell division).

\section{Conclusion}

Leroy Hood writes a metaphor about a group of blind men coming across an elephant. Each one of them touches a different part of the animal and describes it. Even though their guesses miss from the right answer, they make sense from their individual point of view. However, a collaboration and integrated study would likely turn out to reveal the truth [6]. This is a way to understand how interdisciplinarity brings a new perspective on scientific investigation and why domain-specific knowledge is being surpassed by these new methods.

The metaphor was applied by the author on the complexity of biological systems. In addition to that, it can be also applied to life sciences education. The correlation of bioinformatics, interdisciplinary concepts and didactic transposition result in new perspectives on how to address disciplines with a high level of complexity.

The main objectives from such an approach cover both the school life and the student's daily life out of school. The approximation of the student and scientific information encourages the development of critical thinking, a better relationship between students and educators, a deeper investigation of scientific topics, and better understanding of complex disciplines.

A well-versed student can approach scientific information without the fear of not understanding it. Instead, the search for clarifying questions that emerges in the study process may be better addressed. The improvements on life sciences education may be important in this regard, and thus, may help the students on both the school environment and their personal lives.

\section{Acknowledgements}

The authors wish to acknowledge the support of the University of Caxias do Sul while developing this research.

\section{References}

[1] V. Garg, S. Arora, and C. Gupta. "Cloud Computing Approaches to Accelerate Drug Discovery Value Chain.", Combinatorial Chemistry \& High Throughput Screening, CCHTS, 2011, pp. 861-71.

[2] D.A Benson et al. "GenBank", Nucleic Acids Research, 2012, pp. D36-D42.

[3] G. Stoesser et al. "The EMBL Nucleotide Sequence Database", Nucleic Acids Research, Oxford University Press, 2002, pp. 21-26.

[4] L. Hood, "Systems Biology and P4 Medicine: Past, Present, and Future", Rambam Maimonides Medical Journal, 2013, pp. 1-15.

[5] L. da F. Costa, "Bioinformatics: Perspectives for the future", Genetics and Molecular Research. 2004, pp. 564-574.

[6] E. J. H. Spelt et al. "Teaching and Learning in Interdisciplinary Higher Education: A Systematic Review", Educational Psychology Review, 2009, pp. 365-378.

[7] W. H. Newell, "Decision making in interdisciplinary studies", in G. Morçöl (Ed.), Handbook of decision making, New York: CRC, 2007.

[8] W. Callebaut, "Studies in History and Philosophy of Biological and Biomedical Sciences", Studies in History and Philosophy of Biological and Biomedical Sciences, 2012, pp. 69-80.

[9] M. Verret, "Le Temps Des Études", Lille: Atelier Reproduction Des Thèses, Université De Lille III, 1975. 
[10] Y. Chevallard, "La Transposition Didactique: Du Savoir Savant au Savoir Enseigne", Grenoble: La pensee Sauvage, 1985.

[11] C. M. B. Fernandes, "Educação Superior: travessias e atravessamentos", Universidade Luterana do Brasil, Canoas, 2001.

[12] E. Picazzio, "Quando a Divulgação Apenas Desinforma”, Scientific American Brasil, 2008.

[13] D. Gowdak and E. Martins, "Ciências, novo pensar", São Paulo: FTD, 2006.

[14] Franzolin, Fernanda. Conceitos De Biologia $\mathrm{Na}$ Educação Básica E Na Academia: Aproximações E Distanciamentos. Thesis. Faculdade De Educação Da Universidade De São Paulo, 2007. São Paulo, 2007. Print.

[15] A. J. F. Griffiths et al., "Introdução à genética". Rio de Janeiro: Guanabara Koogan, 2006, pp. 743.

[16] Sagan, Carl. The Demon-haunted World: Science as a Candle in the Dark. New York: Ballantine Books, 1997, c1996. Print.

[17] D. N. Kovarik. "Bioinformatics Education in High School: Implications for Promoting Science, Technology, Engineering, and Mathematics Careers". Life Sciences Education. Vol. 12. 2013. pp. 441-459.

[18] O. Folmer, et al. DNA primers for amplification of mitochondrial cytochrome $\mathrm{c}$ oxidase I subunit from diverse metazoan invertebrates. Mol. Mar. Biol. Biotech 3, 1994. pp. 294-299.

[19] P. D. N. Hebert, A. Cywinska, S. L. Ball, J. R. deWaard. Biological identifications through DNA barcodes. Proc R Soc Lond 270, 2003. pp. 313-321.

[20] S. H. Wefer, K. Sheppard. Bioinformatics in High School Biology Curricula: A Study of State Science Standards. Life Sciences Education. Vol. 7, 2008. pp. 155-162.

[21] M. D. Brazas et al. A Quick Guide to Genomics and Bioinformatics Training for Clinical and Public Audiences. Plos Computational Biology. Vol.10 , n. 4. 2014.

[22] E. Banet, E. Ayuso. "Teaching genetics at secondary school: a strategy for teaching about the location of inheritance information". Science Education. 2000, pp. 313.

[23] V. Greenwood. "A Secret Flexibility Found in Life's Blueprints." Quanta Magazine 26 Apr. 2016: Web. 11 July 2016.

[24] Kyrk, J., “Cell Biology Animations”, http://www.john kyrk.com. (Access date: 23 February 2016).

[25] Cold Spring Harbor Laboratory, "DNA from the Beginning", http://www.dnaftb.org. (Access date: 23 February 2016). 